\title{
Five-year incidence of obesity and its determinants: the ATTICA Study
}

\author{
Mary Yannakoulia ${ }^{1, *}$, Demosthenes Panagiotakos ${ }^{1}$, Christos Pitsavos $^{2}$, Yannis Lentzas ${ }^{2}$, \\ Christina Chrysohoou" ${ }^{2}$, loannis Skoumas ${ }^{2}$ and Christodoulos Stefanadis ${ }^{2}$ \\ 'Department of Nutrition and Dietetics, Harokopio University, El. Venizelou 70, Athens 17671, Greece: ${ }^{2}$ First \\ Cardiology Clinic, School of Medicine, University of Athens, Greece
}

Submitted 5 May 2007: Accepted 5 January 2008: First published online 7 March 2008

\begin{abstract}
Objectives: To evaluate the 5-year incidence of obesity in a sample of CVD-free adults and investigate the potential effect of several sociodemographic and lifestyle habits on weight change and obesity incidence in these individuals.

Methods: Men ( $n$ 1514) and women ( $n$ 1528) ( $>18$ years) without any clinical evidence of CVD, living in the Attica area of Greece, were enrolled in the ATTICA study from May 2001 to December 2002. The sampling was random, multistage and included information about various sociodemographic, lifestyle (diet, exercise and smoking), biochemical and clinical characteristics. In 2006, the 5-year follow-up was performed through telephone calls or personal visits. Data from the 1364 participants are analysed in the present work.

Results: The 5-year incidence of obesity was $21.8 \%$ in men and $11.9 \%$ in women. The ratio of men to women revealed that more men than women developed obesity, while more women than men became overweight during the follow-up period. It was found that men were 1.6 times more likely to develop obesity compared with women; abnormal waist circumference, smoking habits and the presence of hypercholesterolaemia increased the risk for developing obesity, irrespective of age and baseline lifestyle characteristics of the participants. In the multivariate analysis, no association was detected between adherence to a Mediterranean diet and incidence of obesity in initially normalweight individuals.

Conclusions: Obesity remains a serious health problem for the Greek population; the alarming rates of excess body weight continue to increase. Preventive measures should be urgently addressed, targeting particularly those with metabolic risk factors.
\end{abstract}

Obesity is becoming a global epidemic, with harmful health, psychosocial and economic effects ${ }^{(1,2)}$. Actions focusing on reducing the prevalence and incidence of obesity and weight gain should constitute a public health priority. Weight gain is associated with increased risk of diabetes, hyperinsulinaemia, insulin resistance, hyperlipidaemia and hypertension ${ }^{(3-8)}$. Several studies have been conducted in order to identify predisposing factors associated with the incidence of weight gain. The existing literature suggests that younger adults, women and African Americans are at higher risk of gaining weight over time and becoming overweight ${ }^{(9-17)}$. Still, the evidence is not conclusive; there are equivocal findings ${ }^{(17,18)}$ and the results may be affected by confounding parameters, such as socio-economic and marital status, changes in smoking habits and physical activity patterns, or inherent sample characteristics and longitudinal changes ${ }^{(19-22)}$. Furthermore, potential 'protective' dietary components contributing to weight maintenance and prevention of weight gain have been identified, i.e. fibre intake ${ }^{(23)}$, breakfast cereals consumption ${ }^{(24,25)}$, vegetable intake ${ }^{(26)}$ and adherence to the Mediterranean $\operatorname{diet}^{(27)}$. Conversely, increased consumption of meat, French fries, dairy products and sweets has been associated with short- or long-term risk for weight gain ${ }^{(25,26,28)}$.

Prospective studies on weight changes and incidence of obesity in population samples in the Mediterranean area are scarce. In the present study we investigated the 5-year incidence and determinants of overweight/obesity, as well as weight gain, in a random sample of CVD-free adults from the ATTICA epidemiological study ${ }^{(29)}$, where a high prevalence of obesity was reported at the baseline evaluation ${ }^{(30)}$. 


\section{Methods}

\section{Study design}

The ATTICA study, a health and nutrition survey, was conducted in the province of Attica (including $78 \%$ urban and $22 \%$ rural areas), Greece, during 2001 to $2002^{(29)}$. The sampling anticipated including only one participant per household; it was random, multistage and based on the age and sex distribution of the province of Attica provided by the National Statistical Service (census of 2001). People living in institutions were excluded from the sampling. From May 2001 to December 2002, 4056 inhabitants from the above area were randomly selected for enrolment into the study. Of them, 3042 agreed to participate ( $75 \%$ participation rate); 1514 of the participants were men and 1528 were women. The selected sample can be considered representative because there were only minor, insignificant differences in sex and age distribution between the study population and the target population. All participants were interviewed by trained personnel (cardiologists, other physicians, dietitians and nurses) on the basis of a standard questionnaire.

\section{Baseline measurements}

At baseline, participants' demographic characteristics (age, sex, mean annual income and years of schooling as a proxy for social status), detailed medical history, dietary and other lifestyle habits (such as smoking and habitual/ leisure-time physical activity) were evaluated. Food consumption was evaluated using the EPIC-Greece questionnaire, a validated semi-quantitative FFQ developed for the Greek cohort of the European Prospective Investigation into Cancer and Nutrition ${ }^{(31)}$. In particular, all participants were asked to report the average intake (per week or day) of several food items that they consumed during the last 12 months. Then, the frequency of consumption was quantified approximately in terms of the number of times a month a food was consumed. Alcohol consumption was measured in wine glasses $(100 \mathrm{ml})$ and quantified by ethanol intake (grams per drink). In order to describe overall dietary patterns, a composite score was used; specifically, a special Mediterranean diet score was applied (range 0-55) based on the rationale of the Mediterranean dietary pyramid ${ }^{(32)}$. Energy intake was assessed using food composition tables ${ }^{(33)}$. Furthermore, the degree of low energy reporting was evaluated by using the ratio of energy intake (EI) to $\mathrm{BMR}^{(34)}$, as described elsewhere ${ }^{(35)}$. Participants with EI:BMR $<1 \cdot 14$ were classified as 'energy under-reporters' or 'low energy reporters'.

Smokers were defined as those who were smoking at least one cigarette daily during the past year or had recently stopped smoking (during a year); the rest of the participants were defined as non-smokers. For the ascertainment of physical activity status, the IPAQ
(International Physical Activity Questionnaire) was used as an index of weekly energy expenditure, using frequency (times per week), duration (in minutes per time) and intensity of sports or other habits related to physical activity (in expended energy per time). Participants who did not report any physical activities were defined as physically inactive (sedentary lifestyle).

Arterial blood pressure was measured three times at the right arm at the end of the physical examination, with subject in sitting position at least for $30 \mathrm{~min}$. Patients whose average blood pressure levels were $\geq 140$ / $90 \mathrm{mmHg}$ or who were under antihypertensive medication were classified as having hypertension ${ }^{(36)}$. In addition, for classification purposes, hypercholesterolaemia was defined as serum total cholesterol level $>200 \mathrm{mg} / \mathrm{dl}$ or the use of lipid-lowering agents ${ }^{(37)}$ and diabetes mellitus as fasting blood glucose level $>125 \mathrm{mg} / \mathrm{dl}$ or the use of antidiabetic medications ${ }^{(38)}$.

Height was measured to the nearest $0.5 \mathrm{~cm}$, without shoes, and weight to the nearest $100 \mathrm{~g}$, without shoes, in light undergarments. BMI was calculated as weight (in kilograms) divided by the square of height (in metres). In accordance with the WHO recommendation ${ }^{(39)}$, overweight was defined as BMI between $25 \cdot 0$ and $29 \cdot 9 \mathrm{~kg} / \mathrm{m}^{2}$, while obesity as was defined as $\mathrm{BMI} \geq 30 \cdot 0 \mathrm{~kg} / \mathrm{m}^{2}$.

The anxious state was assessed using the Spielberger State-Trait Anxiety Inventory (STAI), a twenty-item selfreported questionnaire. The STAI differentiates between the temporary condition of 'state anxiety' and the more general and long-standing quality of 'trait anxiety' ${ }^{,(40,41)}$. The twenty items were rated from 1 to 4 in terms of frequency categories (never; sometimes; often; always) and total scores were obtained by summing the values assigned to each response (range from 20 to 80). Higher scores indicate more trait or state anxiety ${ }^{(40)}$. In the present study, the Greek version of the instrument was used $^{(42)}$. Depressive symptomatology was assessed through a translated version of the Zung Self-Rating Depression Scale (ZSDS), a well-known self-rating scale used worldwide for the measurement of depression ${ }^{(43)}$. The ZSDS consists of twenty items that cover affective, psychological and somatic symptoms (range from 20 to 80 ). Higher scores on this scale are indicative of more severe depression.

\section{Follow-up}

During 2006, the ATTICA study investigators performed the 5-year follow-up of the participants. Of the 3042 initially enrolled participants, vital status was obtained from 1044 men and 1057 women (69\% participation rate). Of them, thirty-two $(2 \cdot 1 \%)$ men and twenty-two $(1 \cdot 4 \%)$ women had died during the 5 -year period. Of the participants who did not participate in the re-examination, $25 \%$ were not found because of missing or wrong addresses and telephone numbers and $5 \%$ refused to be 
re-examined. Participants who were lost to follow-up were more frequently smokers $(P<0 \cdot 001)$ and less physically active $(P=0.03)$ at the baseline examination compared with those who were followed up. No significant differences were observed between those who were lost at follow-up and the rest of the participants regarding sex $(P=0.99)$, baseline age $(P=0 \cdot 78)$, education level in years of schooling $(P=0 \cdot 67)$, as well as the presence of hypertension $(P=0 \cdot 12)$, diabetes $(P=0 \cdot 27)$ and hypercholesterolaemia $(P=0 \cdot 12)$.

The re-examination was based on telephone interviews ( $80 \%$ of the participants) and on face-to-face interviews when a telephone number was not available. The re-examination included self-reported information on vital status (death from any cause or due to CVD), development of CHD or other metabolic conditions among people who did not have these disorders at baseline, body weight and height, and changes in lifestyle habits including dietary intake. For the present analysis, individuals who reported significant dietary changes due to various reasons during the 5-year follow-up period ( $n$ 290), as well as those who did not answer this question about dietary changes during the preceding 5 years ( $n$ 184), were excluded. Moreover, 209 participants reported in the baseline examination that they were on a slimming diet. These participants were also excluded from the present analysis. Furthermore, taking into account those who were lost to follow-up, those who died during the 5-year period and those who were excluded because of the aforementioned reasons, data from 1364 participants are analysed in the present work.

Weight change was used to categorize subjects as weight-stable (those not changing their weight by $>3 \mathrm{~kg}$ in the 5-year period), weight losers (those who decreased their weight by $>3 \mathrm{~kg}$ ) and weight gainers (those who increased their weight by $>3 \mathrm{~kg}$ ). The threshold of $3 \mathrm{~kg}$ for the definition of weight maintenance was based on both statistical and biological bases: it is equivalent to $25 \%$ of the standard deviation of mean body weight of our participants and ensures that an adequate sample is included in the group of weight-stable participants. Furthermore, it represents approximately $4 \%$ of the initial body weight or $0.6 \mathrm{~kg} /$ year, a value that is within the range of values used in studies with prior weight change avoided or unspecified $^{(44)}$.

\section{Statistical analysis}

Continuous variables are presented as mean values with their standard deviation, and categorical variables as absolute and relative frequencies. Associations between categorical variables were tested using the $\chi^{2}$ test. Comparisons of mean values of normally distributed continuous variables between those who lost weight, gained weight or remained weight-stable $( \pm 0 \cdot 25$ sD from baseline BMI or $\pm 3 \mathrm{~kg}$ ) were performed using ANOVA, after controlling for equality of variances using Levene's test. The likelihood for the development of obesity (dependent outcome) during the 5-year period, according to the participants' baseline sociodemographic, lifestyle and clinical characteristics (independent factors), was estimated using odds ratios and their corresponding $95 \%$ confidence intervals through multiple logistic regression analyses. Interactions between sex and other covariates were tested in all steps and, when they were significant, remained in the final model. Deviance residuals were used to evaluate the model's goodness-of-fit, and the $-2 \log$ likelihood of the initial and final model were also calculated. All reported $P$ values are based on two-sided tests and compared with a significance level of $5 \%$. The Statistical Package for Social Sciences statistical software package version 14 (SPSS Inc., Chicago, IL, USA) was used for all statistical calculations.

\section{Results}

During the 5-year follow-up period, $9 \cdot 8 \%$ of men and $7 \cdot 2 \%$ of women participants who were normal-weight at the baseline examination developed obesity ( $n 47)$, while $32.7 \%$ of men and $28.2 \%$ of women who were overweight at baseline developed obesity ( $n$ 105). Thus, the overall 5 -year incidence of obesity was $21 \cdot 8 \%$ in men and $11.9 \%$ in women. The ratio of men to women demonstrated that more men than women developed obesity, while more women than men became overweight; no gender differences were observed regarding the 5-year incidence of overweight or obesity $(P=0 \cdot 10)$. Table 1 illustrates the 5-year incidence of overweight or obesity among study participants who were classified as normalweight at the baseline examination. Middle-aged individuals were more likely to develop obesity during the follow-up period compared with younger or older adults $(P<0 \cdot 001)$. Furthermore, $25 \cdot 7 \%$ of males and $30 \cdot 8 \%$ of females who were obese at baseline remained obese at the 5-year follow-up examination.

During the 5-year period, BMI in men decreased on average by $0.40(\mathrm{SD} 0 \cdot 49) \mathrm{kg} / \mathrm{m}^{2}$, whereas in women it decreased by $0.46($ SD $0 \cdot 49) \mathrm{kg} / \mathrm{m}^{2}$ ( $P$ for gender difference $=0 \cdot 05$ ). When the analysis was stratified by baseline obesity status, it was revealed that, among initially normal-weight participants, the mean change in BMI was $2 \cdot 1$ (sD $3 \cdot 1) \mathrm{kg} / \mathrm{m}^{2}$ in men (i.e. weight gain, $P<0 \cdot 001$ ) and $3 \cdot 1(\mathrm{sD} 3 \cdot 2) \mathrm{kg} / \mathrm{m}^{2}$ in women (i.e. weight gain, $P<0 \cdot 001$ ) ( $P$ for gender difference $=0 \cdot 98$ ), whereas among initially overweight participants the mean change in BMI was $-0 \cdot 85(\mathrm{sD} 3 \cdot 8) \mathrm{kg} / \mathrm{m}^{2}$ in men (i.e. weight loss, $P<0 \cdot 001$ ) and $-0 \cdot 78(\mathrm{sD} 3 \cdot 8) \mathrm{kg} / \mathrm{m}^{2}$ in women (i.e. weight loss, $P=0 \cdot 003$ ) ( $P$ for gender difference $=0 \cdot 72$ ). Similar results were observed among participants classified as obese at baseline; the mean change in BMI was $-4 \cdot 0(\mathrm{sD} 3 \cdot 1) \mathrm{kg} / \mathrm{m}^{2}$ in men (i.e. weight loss, $P<0 \cdot 001$ ) and $-3 \cdot 7(\mathrm{sD} 3 \cdot 1) \mathrm{kg} / \mathrm{m}^{2}$ 
Table 1 Five-year incidence of overweight and obesity among ATTICA study participants classified as normal-weight at the baseline examination

\begin{tabular}{lccrc}
\hline $\begin{array}{l}\text { Baseline age of participants } \\
\text { classified as normal-weight }\end{array}$ & Overweight $(\%)$ & $\begin{array}{c}\text { Ratio of men } \\
\text { to women }\end{array}$ & Obesity (\%) & $\begin{array}{c}\text { Ratio of men } \\
\text { to women }\end{array}$ \\
\hline$<35$ years $(n$ 323) & $47 \cdot 3$ & $0 \cdot 92: 1$ & $5 \cdot 4$ & $1 \cdot 20: 1$ \\
$35-65$ years $(n$ 915) & $44 \cdot 3$ & $0 \cdot 93: 1$ & $10 \cdot 0$ & $1 \cdot 42: 1$ \\
65+ years $(n$ 126) & $45 \cdot 2$ & $1 \cdot 21: 1$ & $3 \cdot 2$ & $\mathrm{~N} / \mathrm{A}$ \\
Overall & $45 \cdot 4$ & $0 \cdot 94: 1$ & $8 \cdot 0$ & $1 \cdot 36: 1$ \\
\hline
\end{tabular}

N/A, not applicable.

Table 2 Results of analyses that evaluated the association between sociodemographic, lifestyle, biological and clinical factors (independent) by group of BMI change in the ATTICA study participants $(n$ 1364)

\begin{tabular}{|c|c|c|c|c|c|c|c|c|c|}
\hline \multirow[b]{2}{*}{ Baseline characteristic } & \multicolumn{2}{|c|}{ Total sample } & \multicolumn{2}{|c|}{ Stable weight } & \multicolumn{2}{|c|}{ Weight gain } & \multicolumn{2}{|c|}{ Weight loss } & \multirow[b]{2}{*}{$P$ for trend } \\
\hline & Mean & SD & Mean & SD & Mean & SD & Mean & SD & \\
\hline$n$ & \multicolumn{2}{|c|}{1364} & \multicolumn{2}{|c|}{212} & \multicolumn{2}{|c|}{529} & \multicolumn{2}{|c|}{623} & \\
\hline Age (years) & 45 & 14 & 45 & 13 & $42^{\star}$ & 14 & $48^{*}$ & 13 & $0 \cdot 001$ \\
\hline Men (\%) & \multicolumn{2}{|c|}{49} & \multicolumn{2}{|c|}{49} & \multicolumn{2}{|c|}{41} & \multicolumn{2}{|c|}{$60^{\star \star}$} & 0.001 \\
\hline Years of schooling & 12 & 4 & 12 & 4 & $13^{*}$ & 4 & 12 & 4 & 0.02 \\
\hline Physical activity (\%) & \multicolumn{2}{|c|}{41} & \multicolumn{2}{|c|}{42} & \multicolumn{2}{|c|}{43} & \multicolumn{2}{|c|}{38} & $0 \cdot 18$ \\
\hline Smoking habits (\%) & \multicolumn{2}{|c|}{41} & \multicolumn{2}{|c|}{33} & \multicolumn{2}{|c|}{$45^{*}$} & \multicolumn{2}{|c|}{38} & 0.002 \\
\hline Obesity (\%) & \multirow{2}{*}{\multicolumn{2}{|c|}{$\begin{array}{l}13 \\
52\end{array}$}} & \multirow{2}{*}{\multicolumn{2}{|c|}{$\begin{array}{r}8 \\
51\end{array}$}} & \multicolumn{2}{|c|}{$2^{*}$} & \multicolumn{2}{|c|}{$27^{\star \star}$} & $<0.001$ \\
\hline WC $>102 / 95 \mathrm{~cm}$ (men/women) $(\%)$ & & & & & \multicolumn{2}{|c|}{34} & \multicolumn{2}{|c|}{$73^{\star \star}$} & $<0.001$ \\
\hline Mediterranean diet score (range $0-55$ ) & 26 & 6 & 26 & 5 & $28^{*}$ & 6 & $24^{*}$ & 5 & 0.001 \\
\hline El:BMR & 1.55 & $0 \cdot 2$ & 1.55 & $0 \cdot 2$ & 1.56 & $0 \cdot 2$ & $1 \cdot 53$ & 0.2 & $0 \cdot 14$ \\
\hline Hypercholesterolaemia (\%) & \multicolumn{2}{|c|}{42} & \multicolumn{2}{|c|}{45} & \multicolumn{2}{|c|}{40} & \multicolumn{2}{|c|}{41} & 0.44 \\
\hline Diabetes, type 2 (\%) & \multirow{2}{*}{\multicolumn{2}{|c|}{$\begin{array}{r}6 \\
28\end{array}$}} & \multirow{2}{*}{\multicolumn{2}{|c|}{$\begin{array}{r}8 \\
26\end{array}$}} & & & & & 0.007 \\
\hline Hypertension (\%) & & & & & & & & & 0.001 \\
\hline Anxiety scale (STAI, range $20-80$ ) & 40 & 12 & 37 & 11 & 40 & 12 & 41 & 12 & $0 \cdot 22$ \\
\hline Depression scale (ZSDS, range $20-80$ ) & 35 & 8 & 33 & 6 & 36 & 8 & 34 & 7 & 0.13 \\
\hline
\end{tabular}

WC, waist circumference; El, energy intake; STAI, Spielberger State-Trait Anxiety Inventory; ZSDS, Zung Self-Rating Depression Scale.

${ }^{\star} P<0.05,{ }^{\star \star} P<0.01$ : Bonferroni-corrected $P$ value for the comparison between the weight gain or weight loss group and those who remained weight-stable during the follow-up period.

in women (i.e. weight loss, $P<0 \cdot 001)$ ( $P$ for gender difference $=0 \cdot 80$ ).

Two hundred and twelve subjects were classified as weight-stable, 623 as weight losers and 529 as weight gainers. Associations of BMI change group (stable weight; weight loss; weight gain) at 5-year follow-up with several sociodemographic, lifestyle, dietary and psychological characteristics are presented in Table 2. Unadjusted analysis showed that compared with those who remained stable, weight losers were more likely to be older, men, obese, with abnormal waist circumference and hypertensive, and had lower adherence to the Mediterranean diet. Moreover, those who gained weight were more likely to be younger, more educated, and less frequently to be obese and/or diabetic (Table 2). It is of interest that those who gained weight were closer to the Mediterranean dietary pattern; however, this association became insignificant in the multivariate analysis, when the EI:BMR ratio was taken into account.

With regard to the incidence of obesity, multiple logistic regression analysis was applied to evaluate the 5-year incidence of obesity among those who were normal-weight or overweight at baseline examination. It was revealed that men were 1.62 times more likely to develop obesity compared with women; abnormal waist
Table 3 Results from multiple logistic regression analyses that evaluated sociodemographic, lifestyle, biological and clinical baseline characteristics in relation to 5-year incidence of obesity in the ATTICA study participants ( $n$ 1364)

\begin{tabular}{lccc}
\hline Factor at baseline examination & OR & $95 \% \mathrm{Cl}$ & $P$ \\
\hline Age (per 1 year) & 1.02 & $0.98,1.05$ & 0.28 \\
Men $v$. women & 1.62 & $1.07,2.45$ & 0.02 \\
WC $>102 / 95 \mathrm{~cm}$ (men/women) & 2.01 & $1.29,3.12$ & 0.002 \\
Physically active $v$. physically inactive & 0.99 & $0.85,1.86$ & 0.25 \\
Smokers $v$. non-smokers & 1.50 & $1.01,2 \cdot 22$ & 0.04 \\
Years of schooling (per 1 year) & 0.99 & $0.94,1.06$ & 0.88 \\
Diabetes (yes/no) & 1.30 & $0.57,2.97$ & 0.54 \\
Hypercholesterolaemia (yes/no) & 1.60 & $1.06,2.41$ & 0.02 \\
Hypertension (yes/no) & 1.50 & $0.96,2.34$ & 0.07 \\
El:BMR & 0.24 & $0.05,1.86$ & 0.08 \\
Mediterranean diet score (per 1 unit) & 0.98 & $0.95,1.03$ & 0.51 \\
\hline
\end{tabular}

WC, waist circumference; El, energy intake.

circumference increased the risk for obesity $2 \cdot 01$-fold, smoking habits increased the aforementioned risk 1.50 fold, and the presence of hypercholesterolaemia at baseline increased the risk for developing obesity 1.60fold, irrespective of age, physical activity, dietary habits and other baseline characteristics of the participants (Table 3). Furthermore, LDL cholesterol levels were associated with obesity incidence, since a $10 \mathrm{mg} / \mathrm{dl}$ difference in baseline levels was associated with $4 \cdot 6 \%$ 
higher likelihood of being obese (OR $=1 \cdot 01,95 \% \mathrm{CI}$ $1 \cdot 00,1 \cdot 02, P=0.001)$. On the contrary, TAG levels were not associated with the development of obesity (OR = $1 \cdot 00,95 \%$ CI $0 \cdot 00,1 \cdot 01, P=0.16$ ); similarly, HDL cholesterol levels were not associated with obesity status at follow-up (OR $=0 \cdot 99,95 \% \mathrm{CI} 0 \cdot 97,1 \cdot 00, P=0 \cdot 32)$.

\section{Discussion}

In the present work the incidence rate of obesity over 5 years was evaluated in a population-based sample of free-living adults. The 5-year incidence of overweight and obesity among volunteers who were classified as normal-weight at baseline examination was $45 \cdot 4 \%$ and $8.0 \%$, respectively; in other words, more than one out of two Greek adults of the ATTICA study developed excess body weight in 5 years. These values are among the highest reported in the literature ${ }^{(10,16,18,45)}$ and the study the first that prospectively examined weight gain and obesity in the Greek population. Ball et al. ${ }^{(10)}$ also recorded a high percentage $(11 \cdot 2 \%)$ of Greek-origin study participants becoming obese in a large multi-ethnic cohort of men and women in Australia, but owing to the nature of the investigation the authors could not presume the contribution of ethnicity or acculturation in their results. In another Mediterranean country, Spain, 7.9\% and $6.9 \%$ of initially overweight women and men respectively became obese, whereas $13 \cdot 8 \%$ and $23 \cdot 0 \%$ of initially normal-weight women and men respectively became overweight, during a 3-year follow-up period according to information collected from the EPIC-Spain cohort $^{(27)}$. Hence, our findings indicate that obesity remains a serious health problem for the Greek population; the alarming rates of excess body weight continue to increase and thus so too does the incidence of weight gain-related metabolic problems.

In the multivariate analysis men were at higher risk to develop obesity during the 5-year follow-up period, a finding which is consistent with the higher prevalence of obesity among men at baseline ${ }^{(30)}$. Dieting is commonly practised among adolescent girls in Greece ${ }^{(46)}$ and we may hypothesize that the interest in slimming may also continue during adulthood, thus explaining, at least in part, the lower incidence of obesity in female study participants despite the higher incidence of overweight. Furthermore, initially normal-weight and overweight participants with central obesity at baseline, as well as with hypercholesterolaemia and smoking, were more prone to become obese. Regardless of educational status, the obesity epidemic disproportionately affects those at cardiovascular risk to become obese and consequently increases their higher risk. Their unfavourable metabolic profile did not prevent them from worsening their health status, despite the recommendations for a healthy lifestyle that had probably been received from health professionals.
Changing dietary and physical activity habits is not an easy task. The adoption of a healthy diet and the attainment of energy balance require a series of behavioural adjustments in eating patterns with regard to meal planning, food selection, food preparation, dining out and portion control, as well as appropriate responses to eating challenges. Similar changes are also required for increasing lifestyle physical activity. It has been suggested that people with risk factors for chronic diseases receive a great amount of information, often confusing and contradictory, from a variety of sources, without respective attention to behavioural changes and the collaborative aspect of intervention, factors that predispose them to low adherence to lifestyle recommendations ${ }^{(47)}$, as was evident from the results of the present study.

Adoption of the Mediterranean diet has been associated with favourable effects on lipoprotein levels, endothelium function, insulin resistance and metabolic syndrome ${ }^{(48)}$. With regard to body weight and obesity status, some investigators have shown that a Mediterranean dietary pattern was inversely related to $\mathrm{BMI}^{(49,50)}$ whereas others did not find any association ${ }^{(51)}$. Prospectively, the findings are also equivocal. High (but not moderate) adherence to a Mediterranean diet was associated with reduced incidence of obesity in a Spanish population ${ }^{(27)}$. In contrast, the dose-response relationship between weight gain and adherence to a Mediterranean dietary pattern observed in the SUN cohort (again a Spanish population sample) became nonsignificant after adjusting for potential confounders; the same was evident when the change in adherence to the Mediterranean diet was used ${ }^{(52)}$. Consistent with the latter work, our analysis did not show an association between the Mediterranean diet score and 5-year incidence of obesity in the multivariate analysis, when confounding factors, including low energy reporting, were taken account. Consequently, the results of the ATTICA study suggest that, even if the Mediterranean dietary pattern has an impact on body weight at a cross-sectional level ${ }^{(49)}$, it does not significantly explain 5-year body weight changes. Previous studies also failed to provide significant associations between dietary factors, either at a nutrient or at a dietary pattern level, with subsequent BMI changes or obesity incidence ${ }^{(11,53,54)}$. Colditz et al. ${ }^{(11)}$ argued that other factors, like age and prior weight loss, were far stronger predictors of weight change than intakes of specific nutrients. Furthermore, due to the nature of the present study, we evaluated obesity incidence only in those participants reporting that their diet remained unchanged during the 5-year follow-up period. One may speculate that changes in dietary patterns would predict changes in anthropometric variables, as previously shown ${ }^{(55)}$, but once a dietary pattern is established this does not account for further weight changes. Finally, several methodological issues have arisen in the literature regarding the use of Mediterranean scores. 
Inclusion of lipid intake in the score or scoring of dairy products and nuts have been proposed as methodological concerns regarding the association between adherence to a Mediterranean diet and obesity ${ }^{(51,52)}$.

The present observational study has some limitations. The baseline evaluation was performed once and may be prone to measurement error; another drawback is the use of self-reported weight and height at follow-up. Although the validity of self-reported anthropometric data has been questioned ${ }^{(56-58)}$, our methodology is similar to those of other cross-sectional surveys and follow-up epidemiological studies in Europe, the USA and Australia $^{(3,10,11,17,26,27,52)}$ and therefore the results are comparable. We paid special attention to include in the analysis only subjects who had stable dietary habits at baseline and also those who firmly reported no change in their diet during the follow-up period. On the other hand, despite the high correlation coefficients between measured and self-reported anthropometric data and the moderate level of agreement between the distributions of self-reported and measured obesity status groups that we have previously found in this population at the baseline assessment ${ }^{(56)}$, we believe that the study possibly provides a conservative estimate of the obesity incidence and that the rates would be higher if information on measured weight was available at follow-up. Another limitation of the study was the response rate of $69 \%$ at follow-up. Participation in epidemiological studies has been declining generally ${ }^{(59)}$; however, our retention rate was among the lowest reported in the literature ${ }^{(3,10,13,27,52,55)}$. Moreover, we observed that participants who were lost to follow-up were more frequently smokers and sedentary at the baseline examination. These findings may bias the final model that evaluated predictors of obesity, since physical inactivity has been reported as a prognostic marker of obesity in some studies. Although this bias may have mediated the lack of significant association between physical activity status and incidence of obesity in our sample, we cannot entirely answer this question from our analysis.

In conclusion, the findings of the 5-year follow-up of the ATTICA study indicate high rates of overweight and obesity incidence in the Greek population. We revealed that initially normal-weight subjects with an unfavourable metabolic profile at baseline were at higher risk for developing obesity prospectively. Preventive measures for excess body weight should be urgently addressed in Greece, with high priority on those with metabolic risk factors.

\section{Acknowledgements}

Authors' contributions and conflict of interest: M.Y. had the concept of the paper, interpreted the results and wrote the paper; D.P. designed the study, supervised the sampling, performed data analysis and wrote the paper; C.P., C.C. and I.S. designed the study, supervised data collection and critically reviewed the paper; Y.L. supervised the follow-up; C.S. supervised the study and critically reviewed the paper. All authors contributed to the final manuscript and none declared any conflict of interest.

Sources of funding: The ATTICA study is supported by research grants from the Hellenic Cardiological Society (HCS2002) and the Hellenic Atherosclerosis Society (HAS2003).

Acknowledgements: The authors would like to thank the field investigators of the ATTICA study: Ioanna Papaioannou, Natassa Katinioti, Akis Zeimbekis, Dina Masoura, Labros Papadimitriou and Spiros Vellas, for their assistance in the physical examination; Charalabos Papageorgiou and Efi Tsetsekou for their assistance in the psychological evaluation; the laboratory team: George Dedousis, Carmen Vassiliadou (genetic analysis), Manolis Kambaxis and Konstadina Palliou, for the nutritional evaluation; Marina Toutouza-Giotsa, Constadina Tselika and Sia Poulopoulou for the biochemical evaluation; and Maria Toutouza for the database management.

\section{References}

1. James PT, Leach R, Kalamara E \& Shayeghi M (2001) The worldwide obesity epidemic. Obes Res 9, Suppl. 4, 228S-233S.

2. Must A, Spadano J, Coakley EH, Field AE, Colditz G \& Dietz WH (1999) The disease burden associated with overweight and obesity. JAMA 282, 1523-1529.

3. Wannamethee SG \& Shaper AG (1999) Weight change and duration of overweight and obesity in the incidence of type 2 diabetes. Diabetes Care 22, 1266-1272.

4. Lee JS, Kawakubo K, Kashihara H \& Mori K (2004) Effect of long-term body weight change on the incidence of hypertension in Japanese men and women. Int $J$ Obes Relat Metab Disord 28, 391-395.

5. Ford ES, Williamson DF \& Liu S (1997) Weight change and diabetes incidence: findings from a national cohort of US adults. Am J Epidemiol 146, 214-222.

6. Lakka HM, Salonen JT, Tuomilehto J, Kaplan GA \& Lakka TA (2002) Obesity and weight gain are associated with increased incidence of hyperinsulinemia in nondiabetic men. Horm Metab Res 34, 492-498.

7. Everson SA, Goldberg DE, Helmrich SP, Lakka TA, Lynch JW, Kaplan GA \& Salonen JT (1998) Weight gain and the risk of developing insulin resistance syndrome. Diabetes Care 21, 1637-1643.

8. Norman JE, Bild D, Lewis CE, Liu K \& West DS (2003) The impact of weight change on cardiovascular disease risk factors in young black and white adults: the CARDIA study. Int J Obes Relat Metab Disord 27, 369-376.

9. Williamson DF (1993) Descriptive epidemiology of body weight and weight change in US adults. Ann Intern Med 119, 646-649.

10. Ball K, Crawford D, Ireland P \& Hodge A (2003) Patterns and demographic predictors of 5-year weight change in a multi-ethnic cohort of men and women in Australia. Public Health Nutr 6, 269-281. 
11. Colditz GA, Willett WC, Stampfer MJ, London SJ, Segal MR \& Speizer FE (1990) Patterns of weight change and their relation to diet in a cohort of healthy women. Am J Clin Nutr 51, 1100-1105.

12. Williamson DF, Kahn HS \& Byers T (1991) The 10-y incidence of obesity and major weight gain in black and white US women aged 30-55y. Am J Clin Nutr 53, 1515S-1518S.

13. Lewis CE, Jacobs Jr DR, McCreath H, Kiefe CI, Schreiner PJ, Smith DE \& Williams OD (2000) Weight gain continues in the 1990s: 10-year trends in weight and overweight from the CARDIA study. Coronary Artery Risk Development in Young Adults. Am J Epidemiol 151, 1172-1181.

14. Rissanen A, Heliovaara M \& Aromaa A (1988) Overweight and anthropometric changes in adulthood: a prospective study of 17,000 Finns. Int J Obes 12, 391-401.

15. Burke GL, Bild DE, Hilner JE, Folsom AR, Wagenknecht LE \& Sidney S (1996) Differences in weight gain in relation to race, gender, age and education in young adults: the CARDIA Study. Coronary Artery Risk Development in Young Adults. Ethn Health 1, 327-335.

16. McTigue KM, Garrett JM \& Popkin BM (2002) The natural history of the development of obesity in a cohort of young US adults between 1981 and 1998. Ann Intern Med 136, 857-864.

17. Sheehan TJ, DuBrava S, DeChello LM \& Fang Z (2003) Rates of weight change for black and white Americans over a twenty year period. Int J Obes Relat Metab Disord 27, 498-504.

18. Vasan RS, Pencina MJ, Cobain M, Freiberg MS \& D'Agostino RB (2005) Estimated risks for developing obesity in the Framingham Heart Study. Ann Intern Med 143, 473-480.

19. Brown WJ, Williams L, Ford JH, Ball K \& Dobson AJ (2005) Identifying the energy gap: magnitude and determinants of 5 -year weight gain in midage women. Obes Res $\mathbf{1 3}$, 1431-1441.

20. Taylor CB, Jatulis DE, Winkleby MA, Rockhill BJ \& Kraemer HC (1994) Effects of lifestyle on body mass index change. Epidemiology 5, 599-603.

21. Williamson DF, Madans J, Anda RF, Kleinman JC, Giovino GA \& Byers T (1991) Smoking cessation and severity of weight gain in a national cohort. $N$ Engl J Med 324, 739-745.

22. Kahn HS, Williamson DF \& Stevens JA (1991) Race and weight change in US women: the roles of socioeconomic and marital status. Am J Public Health 81, 319-323.

23. Ludwig DS, Pereira MA, Kroenke CH, Hilner JE, Van Horn L, Slattery ML \& Jacobs Jr DR (1999) Dietary fiber, weight gain, and cardiovascular disease risk factors in young adults. JAMA 282, 1539-1546.

24. Bazzano LA, Song Y, Bubes V, Good CK, Manson JE \& Liu S (2005) Dietary intake of whole and refined grain breakfast cereals and weight gain in men. Obes Res 13, 1952-1960.

25. Schulz M, Kroke A, Liese AD, Hoffmann K, Bergmann MM \& Boeing H (2002) Food groups as predictors for shortterm weight changes in men and women of the EPICPotsdam cohort. J Nutr 132, 1335-1340.

26. Kahn HS, Tatham LM, Rodriguez C, Calle EE, Thun MJ \& Heath Jr CW (1997) Stable behaviors associated with adults' 10 -year change in body mass index and likelihood of gain at the waist. Am J Public Health 87, 747-754.

27. Mendez MA, Popkin BM, Jakszyn P et al. (2006) Adherence to a Mediterranean diet is associated with reduced 3-year incidence of obesity. J Nutr 136, 2934-2938.

28. French SA, Jeffery RW, Forster JL, McGovern PG, Kelder SH \& Baxter JE (1994) Predictors of weight change over two years among a population of working adults: the Healthy Worker Project. Int J Obes Relat Metab Disord 18, 145-154.

29. Pitsavos C, Panagiotakos DB, Chrysohoou C \& Stefanadis C (2003) Epidemiology of cardiovascular risk factors in
Greece: aims, design and baseline characteristics of the ATTICA study. BMC Public Health 3, 32.

30. Panagiotakos DB, Pitsavos C, Chrysohoou C, Risvas G, Kontogianni MD, Zampelas A \& Stefanadis C (2004) Epidemiology of overweight and obesity in a Greek adult population: the ATTICA Study. Obes Res 12, 1914-1920.

31. Katsouyanni K, Rimm EB, Gnardellis C, Trichopoulos D, Polychronopoulos E \& Trichopoulou A (1997) Reproducibility and relative validity of an extensive semi-quantitative food frequency questionnaire using dietary records and biochemical markers among Greek schoolteachers. Int J Epidemiol 26, Suppl. 1, S118-S127.

32. Panagiotakos DB, Pitsavos C \& Stefanadis C (2006) Dietary patterns: a Mediterranean diet score and its relation to clinical and biological markers of cardiovascular disease risk. Nutr Metab Cardiovasc Dis 16, 559-568.

33. Trichopoulou A \& Georga K (2004) Composition Tables of Simple and Composite Foods. Athens: Parisianos.

34. Goldberg GR, Black AE, Jebb SA, Cole TJ, Murgatroyd PR, Coward WA \& Prentice AM (1991) Critical evaluation of energy intake data using fundamental principles of energy physiology: 1. Derivation of cut-off limits to identify underrecording. Eur J Clin Nutr 45, 569-581.

35. Yannakoulia M, Panagiotakos DB, Pitsavos C, Bathrellou E, Chrysohoou C, Skoumas Y \& Stefanadis C (2007) Low energy reporting related to lifestyle, clinical, and psychosocial factors in a randomly selected population sample of Greek adults: the ATTICA study. J Am Coll Nutr 26, 327-333.

36. Chobanian AV, Bakris GL, Black HR et al. (2003) Seventh report of the Joint National Committee on Prevention, Detection, Evaluation, and Treatment of High Blood Pressure. Hypertension 42, 1206-1252.

37. Expert Panel on Detection, Evaluation, and Treatment of High Blood Cholesterol in Adults (2001) Executive Summary of The Third Report of The National Cholesterol Education Program (NCEP) Expert Panel on Detection, Evaluation, And Treatment of High Blood Cholesterol In Adults (Adult Treatment Panel III). JAMA 285, 2486-2497.

38. American Diabetes Association (2007) Diagnosis and classification of diabetes mellitus. Diabetes Care 30, Suppl. 1, S42-S47.

39. World Health Organization (1997) Obesity: Preventing and Managing the Global Epidemic. Geneva: WHO.

40. Spielberger CD, Gorsuch RL \& Lushene RE (1970) Manual for the State-Trait Anxiety Inventory (STAI). Palo Alto, CA: Consulting Psychologists Press Inc.

41. Anisman H \& Merali Z (2003) Cytokines, stress and depressive illness: brain-immune interactions. Ann Med 35, 2-11.

42. Fountoulakis KN, Papadopoulou M, Kleanthous S, Papadopoulou A, Bizeli V, Nimatoudis I, Iacovides A \& Kaprinis GS (2006) Reliability and psychometric properties of the Greek translation of the State-Trait Anxiety Inventory form Y: preliminary data. Ann Gen Psychiatry 5, 2.

43. Zung WW (1965) A self-rating depression scale. Arch Gen Psychiatry 12, 63-70.

44. Stevens J, Truesdale KP, McClain JE \& Cai J (2006) The definition of weight maintenance. Int J Obes (Lond) $\mathbf{3 0}$, 391-399.

45. Williamson DF, Kahn HS, Remington PL \& Anda RF (1990) The 10-year incidence of overweight and major weight gain in US adults. Arch Intern Med 150, 665-672.

46. Yannakoulia M, Karayiannis D, Terzidou M, Kokkevi A \& Sidossis LS (2004) Nutrition-related habits of Greek adolescents. Eur J Clin Nutr 58, 580-586.

47. Yannakoulia M (2006) Eating behavior among type 2 diabetic patients: a poorly recognized aspect in a poorly controlled disease. Rev Diabetic Stud 3, 11-16. 
48. Serra-Majem L, Roman B \& Estruch R (2006) Scientific evidence of interventions using the Mediterranean diet: a systematic review. Nutr Rev 64, S27-S47.

49. Panagiotakos DB, Chrysohoou C, Pitsavos C \& Stefanadis C (2006) Association between the prevalence of obesity and adherence to the Mediterranean diet: the ATTICA study. Nutrition 22, 449-456.

50. Schroder H, Marrugat J, Vila J, Covas MI \& Elosua R (2004) Adherence to the traditional Mediterranean diet is inversely associated with body mass index and obesity in a Spanish population. J Nutr 134, 3355-3361.

51. Trichopoulou A, Naska A, Orfanos P \& Trichopoulos D (2005) Mediterranean diet in relation to body mass index and waist-to-hip ratio: the Greek European Prospective Investigation into Cancer and Nutrition Study. Am J Clin Nutr 82, 935-940.

52. Sanchez-Villegas A, Bes-Rastrollo M, Martinez-Gonzalez MA \& Serra-Majem L (2006) Adherence to a Mediterranean dietary pattern and weight gain in a follow-up study: the SUN cohort. Int J Obes (Lond) 30, 350-358.

53. Togo P, Osler M, Sorensen TI \& Heitmann BL (2004) A longitudinal study of food intake patterns and obesity in adult Danish men and women. Int J Obes Relat Metab Disord 28, 583-593.
54. Jorgensen LM, Sorensen TI, Schroll M \& Larsen S (1995) Influence of dietary factors on weight change assessed by multivariate graphical models. Int J Obes Relat Metab Disord 19, 909-915.

55. Newby PK, Weismayer C, Akesson A, Tucker KL \& Wolk A (2006) Longitudinal changes in food patterns predict changes in weight and body mass index and the effects are greatest in obese women. J Nutr 136, 2580-2587.

56. Yannakoulia M, Panagiotakos DB, Pitsavos C \& Stefanadis C (2006) Correlates of BMI misreporting among apparently healthy individuals: the ATTICA study. Obesity (Silver Spring) 14, 894-901.

57. Roberts RJ (1995) Can self-reported data accurately describe the prevalence of overweight? Public Health 109, 275-284.

58. Nyholm M, Gullberg B, Merlo J, Lundqvist-Persson C, Rastam L \& Lindblad U (2007) The validity of obesity based on self-reported weight and height: implications for population studies. Obesity (Silver Spring) 15, 197-208

59. Morton LM, Cahill J \& Hartge P (2006) Reporting participation in epidemiologic studies: a survey of practice. Am J Epidemiol 163, 197-203. 